\title{
Sistem Zonasi Penerimaan Peserta Didik Baru dan Dampaknya terhadap Hasil Belajar Bidang Studi Pendidikan Agama Islam di SMP 1 Lubuk Sikaping
}

\author{
Khairil Aftar, Ahmad lahmi, Rahmi \\ Program Pascasarjana, Universitas Muhammadiyah Sumatera Barat
}

Email: khairil.aftar@gmail.com

\begin{abstract}
The Zoning System for New Student Admissions Policy is contained in the Regulation of the Minister of Education and Culture Number 17 of 2017 concerning the Admission of New Students. It is expected to be a solution to achieve educational equality. This study aims to determine the impact of the Student Admissions Zoning System (PPDB) on the Achievements and Learning Outcomes of Students' Islamic Education at SMP Negeri 1 Lubuk Sikaping. The research method in this research is to use a descriptive research method with a qualitative approach. This study uses the comparative after only indicator to determine the impact of the implementation of the Zoning System PPDB policy. The results of this study are, the positive impact of PPDB zoning system is the existence of equitable education, and eliminating school discrimination. The negative impact is the gathering of students with different abilities in one class, this condition makes reducing interest in learning dll. Meanwhile, the factor that becomes an obstacle in implementing the PPDB policy on this zoning system; there are nothing good regulations regarding the implementation of the policy. The policy is not accompanied by an increase in the quality and quality of education, and training of competent educators in all schools.

Keywords: Zoning System; Achievements; Learning outcomes
\end{abstract}

\begin{abstract}
Abstrak
Kebijakan Penerimaan Peserta Didik Baru Sistem Zonasi terdapat pada Peraturan Menteri Pendidikan dan Kebudayaan Nomor 17 Tahun 2017 tentang Penerimaan Peserta Didik Baru, diharapkan menjadi solusi guna mencapai pemerataan pendidikan. Penelitian ini bertujuan untuk mengetahui Dampak Sistem Zonasi Penerimaan Peserta Didik (PPDB) Terhadap Prestasi dan Hasil Belajar PAI Peserta Didik di SMP Negeri 1 Lubuk Sikaping. Metode penelitian pada penelitian ini adalah menggunakan metode penelitian deskriptif dengan pendekatan kualitatif. Penelitian ini menggunakan indikator comparative after only untuk mengetahui dampak dari implementasi kebijakan PPDB Sistem Zonasi. Hasil dari penelitian ini adalah, dampak positif dari PPDB sistem zonasi adalah adanya pemerataan pendidikan, serta menghilangkan diskriminasi sekolah. Dampak negatifnya adalah berkumpulnya siswa dengan kemampuan yang berbedabeda di dalam satu kelas, membuat minat belajar menjadi menurun dll. Sedangkan faktor yang menjadi penghambat dalam penerapan kebijakan PPDB sistem zonasi ini, adalah belum adanya regulasi yang baik mengenai penerapan kebijakan tersebut. Kebijakan tidak disertai dengan peningkatan kualitas dan mutu pendidikan, serta pelatihan tenaga pendidik yang kompeten pada semua sekolah.
\end{abstract}

Kata Kunci: Sistem Zonasi; Prestasi Belajar; Hasil Belajar 


\section{Pendahuluan}

Pendidikan adalah kegiatan usaha sadar dan terencana bisa mewujudkan suasana belajar dan proses pendidikan supaya peserta didik secara aktif meningkatkan kemampuan dirinya untuk mempunyai kekuatan spritual ketaqwaan, pengendalian diri, karakter, kepintaran, akhlaqul Karimah, dan keterampilan yang diperlukan dirinya, keluarga, warga, bangsa serta negara (Pasal 1 dalam Undang-undang Republik Indonesia No 20 Tahun 2003 Tentang Sistem Pendidikan Nasional).

Peserta didik yang telah menamatkan Sekolah Dasar (SD) dan Madrasah Ibtidaiyah (MI) harus melanjutkan ke jenjang pendidikan selanjutnya Sekolah Menegah Pertama ( SMP) atau Madrasah Tsanawiyah (MTs) ${ }^{1}$. Departemen pendidikan Nasional (Depdiknas) telah menggalakkan Wajib Belajar 9 (Sembilan) tahun. Wajib Belajar merupakan program pendidikan minimal yang harus diikuti oleh rakyat Indonesia atas tanggung jawab pemerintah pusat dan pemerintah daerah (pasal 1 Undang-undang Republik Indonesia No.20 Tahun 2003 tentang Sistem Pendidikan Nasional) ${ }^{2}{ }^{3}$. Untuk melanjutkan ke sekolah formal terdapat tahapan yang harus dilewati mulai dari penerimaan peserta didik baru.

Penerimaan peserta didik baru (PPDB) merupakan suatu proses seleksi yang memutuskan diterima atau tidaknya seorang siswa di suatu sekolah ${ }^{4}$. Untuk meningkatkan pemerataan pendidikan diantara upaya pemerintah yakni dengan mengeluarkan program pendidikan baru terkait penerimaan peserta didik baru. Dalam Peraturan menteri pendidikan dan kebudayaan Nomor 17 tahun 2017 kemudian diperbaharui dengan peraturan Menteri Pendidikan dan Kebudayaan nomor 44 tahun 2019 tentang Penerimaan Peserta Didik Baru (PPDB) yang kebijakan tersebut diatur mengenai adanya sistem zonasi yang perlu diperhatikan oleh sertiap sekolah dalam menerima siswa baru ${ }^{5}$.

${ }^{1}$ Nurul Ulfatin, Amat Mukhadis, and Ali Imron, "Profil Wajib Belajar 9 Tahun Dan Alternatif Penuntasannya," Jurnal Ilmu Pendidikan 17, no. 1 (2010): 36-45, http://journal.um.ac.id/index.php/jip/article/view/2618.

2 Wahyudi Barmawi and Suranto Suranto, "Analisis Implementasi Kebijakan Wajib Belajar 9 Tahun Dalam Meningkatkan Mutu Pendidikan Di Kota Ternate," Journal of Governance and Public Policy 3, no. 1 (2016): 176-202, https://doi.org/10.18196/jgpp.2016.0055.

${ }^{3}$ Iyan Fathul Khoeriyah and Achmad Nurmandi, "Evaluasi Program Wajib Belajar 9 Tahun Pada Sekolah Negeri Dan Sekolah Swasta (Studi Kasus Di Sekolah Dasar Negeri Dan Sekolah Dasar Muhammadiyah Di Kota Yogyakarta)," Journal of Governance and Public Policy 1, no. 1 (2014): 190-220, https://doi.org/10.18196/jgpp.2014.0008.

4 David and Nasvizar Guspendri, "Impact of Admission Type on Students' Achievement in Economy and Business School of Batusangkar State Institute of Islamic Studies," Jurnal Penelitian Dan Evaluasi Pendidikan 1, no. 6 (2018): 11-21.

5 Sony Nugratama Hijrawadi et al., "Zoning System Analysis in New Student Admissions Based on the Availability of School Facilities in Bekasi City," Spatial: Wabana Komunikasi Dan Informasi Geografi 2, no. 2 (2020): 45-56. 
Berdasarkan permendikbud nomor 44 tahun 2019, menetapkan soal menerima peserta didik baru (PPDB) berbasis zonasi dengan rincian antara lain ${ }^{6}$; pertama, Jalur Zonasi kuotanya turun menjadi $50 \%$. dari daya tampung Sebelumnya 90\%. Kedua, Jalur Afirmasi bisa mengisi paling sedikit $15 \%$ dari daya tampung sekolah, peserta didik yang masuk melalui jalur afirmasi ini adalah peserta didik yang bertempat tinggal di dalam dan di luar wilayah zonasi sekolah yang bersangkutan. Ketiga, Jalur pindah tempat tugas orang tua/wali paling banyak $5 \%$ dari kemampuan tampung sekolah. Keempat, Jalur Prestasi sebagaimana ditetapkan berdasarkan; Nilai Ujian Sekolah ataupun Nilai Ujian Nasional dan hasil penghargaan atau perlombaan dibidang akademik ataupun non akademik di tingkat Kabupaten/Kota, tingkat Provinsi, tingkat Nasional maupun tingkat Internasional, ini bisa dijadikan salah satu kriteria persyaratan menerima peserta didik baru yang sebelumnya tidak bisa. Adanya penerapan sistem zonasi, lembaga pendidikan yang diselenggarakan oleh pemerintah daerah harus menerima calon peserta didik yang bertempat tinggal pada zona terdekat dari sekolah. Domisili peserta didik tersebut berpatokan dengan alamat yang tercantum dalam kartu keluarga yang terbit paling lambat sebelum satu tahun Penerimaan Peserta Didik Baru (PPDB) .

Dikeluarkannya peraturan menteri tentang sistem zonasi ini diinginkan penerimaan peserta didik baru bisa berjalan dengan baik, tidak ada diskriminasi dan bisa memberikan kesempatan yang sama bagi semua peserta didik untuk menrasakan pendidikan formal, tidak adanya perbedaan kemampuan kognitif ataupun ekonomi yang rendah. Dengan berjalannya aturan tersebut ada beberapa dampak positif dan negatif ${ }^{7}$. Berdasarkan pengamatan penulis di lingkungan sekitar ada beberapa orang tua yang mempunyai anak berkemampuan lebih merasa was-was untuk mendaftarkan anaknya di sekolah favorit tapi di luar daerah domisilinya. Karena jumlah kuota sebesar 15\% untuk jalur prestasi dilihat amat kecil untuk calon peserta didik di luar tempat domisili. Sebab itulah membuat banyak orang tua merasa khawatir untuk mendaftarkan anaknya di luar tempat domisili, dimana sekolah favorit itu berlokasi. Sementara itu sekolah dimana calon peserta didik bertempat tinggal dilihat memiliki fasilitas yang kurang memadai daripada sekolah favorit yang mereka inginkan di luar tempat domisili, sehingga dari permasalahan tersebut kebanyakan orang tua menggunakan beberapa cara demi menyekolahkan anaknya ke sekolah unggulan. SMP Negeri 1 Lubuk Sikaping adalah sekolah unggulan di Kabupaten Pasaman, yang telah menorehkan beberapa prestasi, sehingga menjadi idaman para pencari ilmu untuk menuntut ilmu di sekolah tersebut. Sebaliknya di SMPN 1 Lubuk

6 Gunarti Ika Pradewi and Rukiyati Rukiyati, "Kebijakan Sistem Zonasi Dalam Perspektif Pendidikan," Jurnal Manajemen Dan Supervisi Pendidikan 4, no. 1 (2019): 28-34, https://doi.org/10.17977/um025v4i12019p028.

${ }^{7}$ Gede Danu Setiawan and Ni Luh Yaniasti, "Sistem Zonasi Sekolah: Antara Persepsi Dan Minat Belajar Siswa," Indonesian Journal of Learning Education and Counseling 3, no. 2 (2021): 183-93, https://doi.org/10.31960/ijolec.v3i2.902. 
Sikaping sebelum adanya sistem zonasi banyak menerima murid dari jalur prestasi.

Dari penelitian terdahulu yang relevan dengan permasalahan yang akan diteliti tentang Sistem Zonasi PPDB seperti riset yang dibuat oleh Desi Wulandari (2018), mengambil tema Pengaruh Penerimaan Peserta Didik Baru Melalui Sistem Zonasi Terhadap Prestasi Belajar Siswa Kelas VII Di SMPN 1 Labuhan Ratu Lampung Timur Tahun Pelajaran 2017 /2018. Dari penelitian ini ditemukan adanya beberapa permasalahan yang timbul dengan adanya system zonasi di antaranya peserta didik yang diterima melalui sistem zonasi memiliki kemampuan kognitif serta motivasi belajar cukup rendah dibandingkan peserta didik diterima melalui jalur prestasi. Serta para guru yang cukup kesulitan menghadapi murid-murid dengan kemampuan kognitif yang berbeda-beda karena sudah terbiasa mengajar murid dengan kemampuan kognitif yang tinggi ${ }^{8}$.

Pendekatan penelitian yang digunakan adalah pendekatan penelitian kualitatif yang bersifat deskriptif ${ }^{9}$. Jadi prosedur riset ini, hendak menghasilkan informasi deskriptif, berbentuk kata-kata tertulis ataupun lisan dari orang- orang serta sikap yang bisa diamati. Penelitian deskriptif kualitatif ini bertujuan buat mengetahui sesuatu kondisi atau keadaan secara apa adanya.

Riset ini dilaksanakan di SMP Negeri 1 Lubuk Sikaping Kabupaten Pasaman. Waktu penelitian akan digunakan untuk meneliti adalah selama peneliti melakukan proses penelitian, dimana diawal dari tahap persiapan sampai dengan tahap penyusunan. SMP Negeri 1 Lubuk Sikaping Kabupaten Pasaman dipilih sebagai tempat penelitian karena di SMP Negeri 1 Lubuk Sikaping Kabupaten Pasaman ini telah dilaksanakan PPDB dengan siterm Zonasi. Di samping itu, SMP Negeri 1 Lubuk Sikaping Kabupaten Pasaman selama ini menjadi sekolah favorit di Kabupaten Pasaman dengan banyaknya anak yang berprestasi memilih sekolah itu.

Subjek evaluasi dari pada penelitian ini yaitu beberapa peserta didik yang diterima di lembaga pendidikan yang melalui sistem zonasi (PPDB) dan beberapa siswa yang bukan diterima melalui sistem zonasi (Konvensional) serta guru dan orang tua karena merupakan faktor yang utama dan sangat berpengaruh dalam berjalannya program tersebut dan sesuai dengan judul penelitian. Objek evaluasi dari penelitian ini adalah Dampak Sistem Zonasi

${ }^{8}$ Desi Wulandari, Adelina Hasyim, and Yunisca Nurmalisa, "Pengaruh Penerimaan Peserta Didik Baru Melalui Sistem Zonasi Terhadap Prestasi Belajar Siswa," Jurnal Kultur Demokrasi 2, no. 1 (2018): 1-13, http://link.springer.com/10.1007/978-3-319-768878\%0Ahttp://link.springer.com/10.1007/978-3-319-93594-

2\%0Ahttp://dx.doi.org/10.1016/B978-0-12-409517-5.00007-

3\%0Ahttp://dx.doi.org/10.1016/j.jff.2015.06.018\%0Ahttp://dx.doi.org/10.1038/s41559-0190877-3\%0Ahttp://dx.do.

9 Frederick Parente, John-Christopher Finley, and Christopher Magalis, "An Association Rule General Analytic System (ARGS) For Hypothesis Testing in Qualitative and Quantitative Research," International Journal of Quantitative and Qualitative Research Methods 9, no. 1 (2021): 1-13. 
Penerimaan Peserta Didik Baru Terhadap Prestasi dan Hasil Belajar PAI Peserta Didik.

Dalam penelitian ini memakai dua variabel penelitian, yakni Variabel prestasi belajar peserta didik dan Variabel hasil belajar para peserta didik yang masuk sekolah melalui sistem zonasi di SMP Negeri 1 Lubuk Sikaping.

Adapun yang menjadi indikator variabel tersebut adalah: 1) Hasil Belajar siswa, 2) Penilaian dari hasil belajar Mata Pelajaran PAI di SMP Negeri 1 Lubuk Sikaping Kabupaten Pasaman. 3) Presatasi Belajar peserta didik.

Data yang dipakai dalam penelitian ini diperoleh dari data primer serta data sekunder. Data primer didapat melalui cara obsevasi dan wawancara kepada informan penelitian yaitu orang tua peserta didik, dewan pendidikan kabupaten pasaman, pengamat pendidikan kabupaten pasaman dan pendidik dan kepala sekolah SMP Negeri 1 Lubuk Sikaping. Adapun data sekunder pada penelitian ini berasal dari Dokumen SMP Negeri 1 Lubuk Sikaping, informasi pengelolaan pemerataan layanan pembelajaran di sekolah dan wawancara pihak pemangku kepantingan di sekolah berhubungan dengan dampak sistem zonasi.

Di bawah ini adalah penggunaan kode buat sumber data yang diperlukan pada penelitian ini.

Tabel 1. Tabel Kode Pengumpulan Data

\begin{tabular}{|c|l|l|}
\hline No & \multicolumn{1}{|c|}{$\begin{array}{c}\text { Kategori Pengumpulan } \\
\text { Data }\end{array}$} & \multicolumn{1}{c|}{ Kode } \\
\hline 1 & Observasi & (O/No K/Tempat/Tanggal) \\
\hline 2 & Wawancara & (W/ Nama/Jab/NoSPP/Tanggal) \\
\hline 3 & Dokumentasi & (D/Sumber/Nama Dokumen/Tanggal) \\
\hline
\end{tabular}

Keterangan $\mathrm{O}=$ Observasi, $\mathrm{W}=$ Wawancara, $\mathrm{D}=$ Dokumentasi, Nama $=$ Nama reponden diwawancara, Nama dok = Nama dokumentasi, Jab = Jabatan responden, No SPP $=$ No subjek partisipan penelitian, Tanggal $=$ tanggal pengumpulan data, Tempat $=$ tempat observasi, Sumber $=$ sumber memendapatkan dokumentasi, no $\mathrm{K}=$ Nomor kegiatan yang dilaksanakan

\section{Tabel 2 Tabel Responden Wawancara}

\begin{tabular}{|c|l|l|}
\hline No & \multicolumn{1}{|c|}{ Responden } & \multicolumn{1}{|c|}{ Keterangan } \\
\hline 1 & $\begin{array}{l}\text { Kepala Sekolah SMP } \\
\text { Negeri 1 Lubuk } \\
\text { Sikaping }\end{array}$ & $\begin{array}{l}\text { Tentang Dampak Sistem Zonasi } \\
\text { Penerimaan Peserta Didik Baru (PPDB) }\end{array}$ \\
\hline 2 & $\begin{array}{l}\text { Wakil Kepala Sekolah } \\
\text { sekaligus sebagai ketua } \\
\text { panitia PPDB }\end{array}$ & $\begin{array}{l}\text { Tentang Dampak Sistem Zonasi Penerimaan } \\
\text { Peserta Didik Baru (PPDB) Terhadap prestasi } \\
\text { peserta didik }\end{array}$ \\
\hline 3 & Guru PAI & $\begin{array}{l}\text { Tentang Dampak Sistem Zonasi Penerimaan } \\
\text { Peserta Didik Baru (PPDB) Terhadap Hasil } \\
\text { Belajar PAI Peserta Didik di SMP Negeri 1 } \\
\text { Lubuk Sikaping }\end{array}$ \\
\hline 4 & Peserta didik kelas VII & Tentang proses belajar \\
\hline
\end{tabular}


Data dari lapangan yang sudah diperoleh dan terkumpul, pekerjaan yang harus dilakukan penulis selanjutnya adalah mengalalis data tersebut dengan cara mengelompokkannya dan mengurutkan ke dalam sebuah pola, sehingga dapat ditemukan tema serta dapat dirumuskan hipotesis kerja seperti yang disarankan dalam data tersebut. Dalam menganalisis data yang telah terkumpul, penulis menggunakan analisis deskriptif kualitatif. Metode analisis deskriptif yaitu suatu analisis yang digambarkan dengan kata-kata atau kalimat yang dipisahkan menurut kategori guna mendapat kesimpulan. Sedangkan analisis data dari hasil penelitian ini, dilakukan berdasar analisis deskriptif, sebagaimana yang dikembangkan oleh Mile dan Huberman. Analisis tersebut terdiri atas tiga alur analisis yang berinteraksi yaitu reduksi data, penyajian data dan penarikan kesimpulan.

\section{Hasil dan Pembahasan}

Dampak positif yang dirasakan setelah dibuat peraturan penerimaan peserta didik baru dengan sistem zonasi yaitu adanya kepastian bagi peserta didik yang bertempat tinggal dekat dengan sekolah apalagi yang satu kenagarian, karena sistem zonasi memprioritaskan jarak tempat tinggal. Untuk sekolah yang biasanya kekurangan peserta didik sebelum diberlakukannya sistem zonasi, maka setelah diberlakukannya sistem zonasi sekolah tersebut tidak takut lagi kekurangan peserta didik bahkan sekolah tersebut mendapatkan peserta didik yang berprestasi juga seperti sekolah favorit.

Meringankan tugas sekolah, mengurangi keterlambatan, komunikasi dengan orang tua lebih mudah dikarenakan jarak rumahnya yang dekat dengan sekolah $^{10}$. Tidak ada diskriminasi dan berkeadilan, maksud dari tidak adanya diskriminasi dan berkeadilan adalah bahwa sebelum ditetapkannya sistem zonasi yang berhak untuk masuk ke sekolah tersebut adalah siswa yang pintar-pintar dan sekolah lain mendapatkan "sisanya" bahkan ada yang kekurangan siswa tidak memandang nilai dan status ${ }^{11}$. Yang terakhir adalah lebih menghemat biaya untuk sekolah, karena yang biasanya ke sekolah menggunakan alat transportasi yang mengeluarkan uang contoh naik angkutan umum/oplet sekarang tidak lagi atau yang sangat berharap sekolah disitu akhirnya sampai harus mengeluarkan uang buat kos sekarang tidak diperlukan lagi.

Disisi lain, dampak negatif dari sistem zonasi yang Pertama adalah siswa yang nilainya bagus tidak dapat diterima dikarenakan terhalang oleh jarak, mau ikut ke jalur zonasi tidak bisa karena terhalang oleh siswa yang jaraknya lebih dekat dengan sekolah. Semua peraturan pasti akan menguntungkan dan

${ }^{10}$ Dian Purwanti et al., "Implementation of Zoning System Policy for New Students Admission," in PROCEEDING INTERNATIONAL CONFERENCE ON SOCLAL SCIENCES Faculty of Social Sciences and Political Sciences, Universitas Mubammadiyah Jakarta The 2nd International Conference on Social Science 2019 Jakarta, 5-6 November 2019 Indonesia, 2019, 255-62.

11 Maurish Sofie, "A Study of Student Admission by School Zoning System in Indonesia: Problem or Solution?” (Taiwan, 2020). 
merugikan, sistem zonasi ini merugikan untuk siswa yang rumahnya ditengahtengah kesana sini jauh sekalinya lumayan dekat kalah dengan siswa yang lebih dekat apalagi didaerahnnya tidak ada sekolah negeri. Satu- satunya cara adalah dengan mendapatkan nilai yang sangat baik atau tidak melalui dua jalur lagi yang sudah ditentukan yaitu afirmasi dan perpindahan orangtua itu pun harus bersaingan dengan peserta didik yang radius alamatnya dekat dengan sekolah.

Kedua, tidak bisanya menyeleksi pendaftar berdasarkan nilai, berapapun nilainya mau tidak mau sekolah harus menerima siswa tesebut. Hal ini terjadi karena semuanya sudah diatur oleh pemerintah bahkan yang menyeleksinya pun dari pemerintah atau sistem. Dengan sistem zonasi ini dapat memicu bergabungnya peserta didik secara heterogen yang mempunyai multi kemampuan. Dengan berkumpulnya peserta didik yang mempunyai tingkat kemampuan yang berbeda-beda, ada yang mempunyai kemampuan akademik yang tinggi ada pula yang rendah. Mereka bertemu disatu sekolah bisa juga menjadi satu ruangan kelas. Dengan adanya perbedaan ini menjadi suatu tantangan bagi guru bisa mencari strategi mengajar yang tepat yang dapat menjawab permasalahan tersebut.

Ketiga, Peserta didik yang mempunyai prestasi akademik tinggi biasanya telah menguasai materi dasar hingga peserta didik tersebut akan merasa cepat jenuh $^{12}$, tidak bersemangat dan kurang terpacu ${ }^{13}$, hingga mereka yang mempunyai prestasi akademik tinggi akan cenderung meremehkan dan malas, hal tersebut memberi dampak negatif terhadap proses pembelajaran peserta didk tersebut. Sebaliknya materi ajar yang tinggi serta mendalam tidak pas jika diajarkan pada peserta didik yang mempunyai kemamampuan akademik rendah, sebab mereka akan bingung. Hal yang demikian akan menimbulkan masalah baru dalam proses belajar mengajar.

Dari pembahasan di atas bisa diambil kesimpulan bahwasannya sistem zonasi penerimaan peserta didik baru belum maksimal, disebabkankan masih adanya hambatan-hambatan yang dirasakan saat pelaksanaan penerimaan peserta didik baru.Di samping itu sistem zonasi yang dilaksanakan terdapat juga dampak positif dan negatifnya.sDi SMP Negeri Lubuk Sikaping sendiri dirasakan dampak positifnya dimana untuk keterlambatan siswa akan bisa diatasi karena jarak rumah dan sekolah begitu dekat, kemudian komunikasi kondusif akan mudah terjalin antara pihak sekolah dengan orang tua,sementara dampak negatifnya juga dirasakan karena anak yang masuk sekolah sudah heterogen

12 Rosniati Hakim et al., "Institute Quality Improvement Through Management Training of Accreditation Preparation in TK Aisyiyah Bustanul Athfal Padang," in Proceedings of the International Conference of Early Childhood Education (ICECE 2019) Institute, vol. 44 (ATLANTIS PRESS Advances in Social Science, Education and Humanities Research (ASSEHR), 2020), 55 65, https://doi.org/10.2991/assehr.k.200715.012.

13 Fitria Sartika, Elni Desriwita, and Mahyudin Ritonga, "Pemanfaatan Media Pembelajaran Dalam Meningkatkan Kualitas Pembelajaran PAI Di Sekolah," Humanika, Kajian Ilmiah Mata Kuliah Umum 20, no. 2 (2020): 115-28, https://doi.org/10.21831/hum.v20i2.32598. 
dengan kemampuan yang berbeda, sehingga pihak sekolah harus ektra kerja keras untuk meningkatkan mutu sekolah agar tetap dapat di pertahankan.

SMP Negeri 1 Lubuk Sikaping yaitu salah satu sekolah favorit yang ada di kabupaten pasaman, sekolah yang menjadi incaran bagi peserta didik maupun orang tuanya. Bahkan siswa bersedia berpisah tempat tinggal dengan orang tuanya atau kost untuk dapat bersekolah di SMP Negeri 1 Lubuk Sikaping. Hal tidak terlepas dari mutu sekolah yang baik dan prestasi siswa yang tinggi, seperti yang telah diungkapkan di atas tentang prestasi yang sudah diraih oleh siswa dan guru. Sewaktu peneliti menanyakan kepada responden tentang adakah dampak zonasi terhadap tingkat prestasi siswa yang ada di SMP Negeri 1 Lubuk sikaping sebab sebelum zonasi mereka menerima siswa lebih $90 \%$ dari jalur prestasi, sehingga anak yang masuk ke sekolah itu adalah anak pilihan yang mudah untuk di atur. Responden menjawab kalau sekarang masa pandemi, anak selama ini melakukan belajar secara luring di rumah dan kegiatan-kegiatan perlombaan pun banyak yang ditunda dan ditiadakan, sehingga amat sulit sekali menentukan apakah dampak zonasi itu membuat prestasi siswa baik atau turun.

Ditempat terpisah hal yang sama juga dinyatakan waka sekolah bidang kesiswaan dimana adanya pengaruh yang dirasakan, karena sudah bercampurnya siswa yang masuk ke SMP Negeri 1 lubuk Sikaping walaupun dampat tersebut tidak terlalu signifikan. Sebab setiap anak itu mempunyai kemampuan yang berbeda, ketika seorang siswa lemah dibidang akademik tapi ia kuat dibidang non akademik.

Berdasarkan pembahasan yang telah diperoleh, maka bisa disimpulkan bahwa dampak PPDB sistem zonasi terhadap prestasi peserta didik di SMP Negeri 1 Lubuk Sikaping memang ada dirasakan, tapi itu tidak signifikan, masih dapat diatasi oleh para pendidik dengan memacu prestasi para siswa.

Dampak sistem zonasi terhadap hasil belajar peserta didik di SMP Negeri 1 Lubuk Sikaping berdasarkan yang telah di ungkapkan respoden pada wawancara di atas, memang terdampak di awal diberlakukannya sistem zonasi oleh pemerintah, karena SMP Negeri 1 Lubuk Sikaping yaitu salah satu sekolah favorit yang ada di Kabupaten Pasaman. Sebelum dilakukannya sitem zonasi, sekolah ini menerima peserta didik baru dari jalur prestasi, sedikit banyaknya berpengaruh terhadap proses belajar mengajar yang berlangsung di kelas. Setelah pemerintah mewajibkan seluruh sekolah dalam penerimaan peserta didik baru harus dengan sistem zonasi yang otomatis peserta didik masuk ke dalam sekolah tersebut sudah heterogen dari asal sekolah yang berbeda dan kemampuan yang tidak sama. Sehingga ketika dikonfirmasi kepada guru PAI, memang terasa sedikit perubahan menghadapi anak yang masuk jalur prestasi dengan anak yang masuk jalur zonasi. Untuk itu para pendidik harus mengubah pola mengajar mereka dari yang dahulu. Tapi di era pandemi cukup sulit menilai hasil belajar peserta didik tersebut, karena sistem belajar daring, kita tidak bertatap muka dengan anak sehingga sulit menentukan anak yang betul-betul mampu dalam 
belajar dan mana anak yang tidak mampu dalam belajar karena semua tugas dikerjakan di rumah tanpa pengawasan dari pendidik.

Pemberlakuan sistem zonasi memiliki dampak terhadap hasil pembelajaran Pendidikan Agama Islam, karena peserta didik, jika sebelum pemberlakuan sistem zonasi ini peserta didik mayoritas memiliki kemampuan yang sama, maka dengan sistem zonasi kemampuan peserta didik semakin heterogent.

Jadi dapat kita simpulkan bahwa SMP Negeri 1 Lubuk Sikaping juga merasakan dampak penerimaan peserta didik baru melalui sistem zonasi terhadap hasil belajar PAI para siswa di sekolah ini. Walaupun dampak yang dirasakan tidak signifikan karena dihadapkan dengan masalah pandemi covid 19 sekarang ini. Dalam proses belajar mengajar prihal tersebut juga dialami oleh pendidik, sebab harus ekstra manghadapi peserta didik yang berbeda latar belakang kemampuannya.

\section{Penutup}

Penelitian mengenai Dampak Sistem Zonasi Penerimaan Peserta Didik Baru (PPDB) Terhadap Prestasi dan Hasil Belajar PAI Peserta Didik di SMP Negeri 1 Lubuk Sikaping, berpatokan pada temuan dan pembahasan penelitian yang telah diuraikan dalam bab IV, sebagaimana temuan-temuan di lapangan yang di bahas dengan teori-teori yang ada dengan fokus penelitian pada dampak zonasi terhadap prestasi dan hasil belajar PAI peserta didik di SMP Negeri 1 Lubuk Sikaping, maka dapat diambil kesimpulan yakni:

Pertama, Terdapatnya pengaruh sistem zonasi terhadap para peserta didik, baik itu dampak positif maupun dampak negatif yang ditimbulkan. Dampak positif seperti semakin dekatnya jarak peserta didik dengan sekolah. Semakin mudahnya komunikasi guru dengan wali murid karena jarak sekolah yang lebih dekat dengan rumah siswa. Tercukupinya kuota peserta didik pada suatu sekolah serta peserta didik yang lebih terdiversifikasi karena adanya komposisi ssiwa yang berbeda dalam satu sekolah baik yang memiliki kemampuan akademik tinggi dan kemampuan akademik yang kurang dalam satu sekolah yang sama sehingga adanya pembagian siswa yang merata pada tiap sekolah.

Kedua, Dampak negatif sistem zonasi terhadap peserta didik yaitu; pertama siswa tidak dapat memilih sekolah mana yang diinginkan karena terhalang jarak tempat tinggal yang lebih jauh,. Kedua, sekolah tidak dapat menyeleksi siswa berdasarkan nilai masing-masing siswa sehingga siswa yang masuk dalam suatu sekolah terdiri dari berbagai kemampuan akademik. Ketiga, adanya ketimpangan kemampuan murid dalam memahami system pembelajaran dimana siswa yang memiliki kemampuan akademik yang baik cenderung menyepelekan pembelajaran. Sebaliknya hal-hal yang terlalu mendalam tidak dapat pula diterima dengan baik oleh siswa yang memiliki kemampuan akademik rendah. 
Ketiga, Dengan diterapkannya sistem zonasi, pemerintah harus mampu dalam memfasilitasi setiap sekolah dengan fasilitas yang sama dan merata karena kembali pada tujuan sistem zonasi ialah meningkatkan pemertaan bagi masingmasing sekolah. Sehingga mutu setiap sekolah juga akan semakin meningkat. Keempat, Terdapatnya dampak sistem PPDB dengan sistem zonasi terhadap prestasi murid karena kemampuan para murid yang berbeda pada setiap sekolah. Dampak ini tidak terlalu signifikan dan masih dapat diatasi dengan memacu kemampuan prestasi peserta didik.

Kelima, Adanya dampak sistem zonasi terhadap hasil pelajaran PAI. Asal sekolah para murid yang berbeda sehingga mempengaruhi proses belajar mengajar guru PAI. Sehingga para guru harus mengubah pola mengajar agar dapat diterima setiap peserta didik. Para guru juga merasakan perbedaan hasil belajar PAI peserta didik sebelum dan sesudah system zonasi walaupun perbedaanya tidak terlalu besar.

\section{Bibliografi}

Barmawi, Wahyudi, and Suranto Suranto. "Analisis Implementasi Kebijakan Wajib Belajar 9 Tahun Dalam Meningkatkan Mutu Pendidikan Di Kota Ternate." Journal of Governance and Public Policy 3, no. 1 (2016). https://doi.org/10.18196/jgpp.2016.0055.

David, and Nasvizar Guspendri. 'Impact of Admission Type on Students' Achievement in Economy and Business School of Batusangkar State Institute of Islamic Studies." Jurnal Penelitian Dan Evaluasi Pendidikan 1, no. 6 (2018).

Fathul Khoeriyah, Iyan, and Achmad Nurmandi. "Evaluasi Program Wajib Belajar 9 Tahun Pada Sekolah Negeri Dan Sekolah Swasta (Studi Kasus Di Sekolah Dasar Negeri Dan Sekolah Dasar Muhammadiyah Di Kota Yogyakarta)." Journal of Governance and Public Policy 1, no. 1 (2014). https://doi.org/10.18196/jgpp.2014.0008.

Gede Danu Setiawan, and Ni Luh Yaniasti. "Sistem Zonasi Sekolah: Antara Persepsi Dan Minat Belajar Siswa." Indonesian Journal of Learning Education and Counseling 3, no. 2 (2021). https://doi.org/10.31960/ijolec.v3i2.902.

Hakim, Rosniati, Khadijah, Mahyudin Ritonga, Weti Susanti, and Rahmi. "Institute Quality Improvement Through Management Training of Accreditation Preparation in TK Aisyiyah Bustanul Athfal Padang." In Proceedings of the International Conference of Early Childhood Education (ICECE 2019) Institute, 44:55-65. ATLANTIS PRESS Advances in Social Science, Education and Humanities Research (ASSEHR), 2020. https://doi.org/10.2991/assehr.k.200715.012.

Hijrawadi, Sony Nugratama, Adrian, Ramadhan Syahrul, and Amalia Yustika. 
"Zoning System Analysis in New Student Admissions Based on the Availability of School Facilities in Bekasi City." Spatial: Wahana Komunikasi Dan Informasi Geografi 2, no. 2 (2020).

Parente, Frederick, John-Christopher Finley, and Christopher Magalis. "An Association Rule General Analytic System (ARGS) For Hypothesis Testing in Qualitative and Quantitative Research." International Journal of Quantitative and Qualitative Research Methods 9, no. 1 (2021).

Pradewi, Gunarti Ika, and Rukiyati Rukiyati. "Kebijakan Sistem Zonasi Dalam Perspektif Pendidikan." Jurnal Manajemen Dan Supervisi Pendidikan 4, no. 1 (2019). https://doi.org/10.17977/um025v4i12019p028.

Purwanti, Dian, Ira Irawati, Herijanto Bekti, and Josy Adiwisastra. "Implementation of Zoning System Policy for New Students Admission." In PROCEEDING INTERNATIONAL CONFERENCE ON SOCLAL SCIENCES Faculty of Social Sciences and Political Sciences, Universitas Muhammadiyah Jakarta The 2nd International Conference on Social Science 2019 Jakarta, 5-6 November 2019 Indonesia, 2019.

Sartika, Fitria, Elni Desriwita, and Mahyudin Ritonga. "Pemanfaatan Media Pembelajaran Dalam Meningkatkan Kualitas Pembelajaran PAI Di Sekolah.” Humanika, Kajian Ilmiah Mata Kuliah Umum 20, no. 2 (2020): 115-28. https://doi.org/10.21831/hum.v20i2.32598.

Sofie, Maurish. "A Study of Student Admission by School Zoning System in Indonesia: Problem or Solution?” Taiwan, 2020.

Ulfatin, Nurul, Amat Mukhadis, and Ali Imron. "Profil Wajib Belajar 9 Tahun Dan Alternatif Penuntasannya." Jurnal Ilmu Pendidikan 17, no. 1 (2010). http://journal.um.ac.id/index.php/jip/article/view/2618.

Wulandari, Desi, Adelina Hasyim, and Yunisca Nurmalisa. "Pengaruh Penerimaan Peserta Didik Baru Melalui Sistem Zonasi Terhadap Prestasi Belajar Siswa." Jurnal Kultur Demokrasi 2, no. 1 (2018). http:/ /link.springer.com/10.1007/978-3-319-76887-

8\%0Ahttp://link.springer.com/10.1007/978-3-319-93594-

2\%0Ahttp://dx.doi.org/10.1016/B978-0-12-409517-5.00007-

3\%0Ahttp://dx.doi.org/10.1016/j.jff.2015.06.018\%0Ahttp://dx.doi.org /10.1038/s41559-019-0877-3\%0Ahttp://dx.do. 